\title{
FEA Analysis for Scissor Lifting Table
}

\author{
V.Giridharan', M.Ramakrishna' ${ }^{2}$ B.Vikram \\ 1,2,3 Assistant Professor, Department of Aeronautical Engineering, Bharath Institute of Higher Education and \\ Research, Chennai.
}

Article History: Received: 11 January 2021; Accepted: 27 February 2021; Published online: 5 April 2021

\begin{abstract}
The main goal of the project is weight analysis of scissor lifting table in the ware house, the scissor lifting table is a common device for all kind of peoples, we go to do the structural analysis of the scissor lifting table with the various human weights scissor lifting table modelled in Solid works software and structural analysis of human weights $50 \mathrm{~kg}, 75 \mathrm{~kg}, 100 \mathrm{~kg}$ and $125 \mathrm{~kg}$ done in ANSYS workbench software
\end{abstract}

KEYWORDS: Scissor lifting table, human weight analysis, ANSYS, FEA Analysis

\section{INTRODUCTION:}

The objective of Lift tables design is to raise or lower goods and/or persons through relatively small distances. Its applications include pallet handling, vehicle loading and work positioning and helps to reduce incidents of Musculo skeletal disorders by correctly re-positioning work at a suitable height for operators. Apart from above mentioned uses they can work in hostile environments, the material used for its design is stainless steel. Barriers, conveyors, turntables, and gates are the equipment necessary to assemble lift table.

In this research work design the lift table with proper dimensions using solid work and analyze that table with various human weights using FEM, while taking the stress, deflection and safety factor for different load condition we conclude the lift table system is safest for all load condition.

\section{MATERIALS AND METHODS:}

\section{Steel}

Steel is an alloy of iron with typically a few percent of carbon to improve its strength and fracture resistance compared to iron. Many other additional elements may be present or added. Stainless steels that are corrosion and oxidation resistant need typically an additional $11 \%$ chromium.

Table 1. Material Properties

\begin{tabular}{|c|c|c|c|}
\hline & $\begin{array}{c}\text { DENSITY } \\
\left(\text { KG/M }^{\mathbf{3}}\right)\end{array}$ & $\begin{array}{c}\text { YOUNG'S } \\
\text { MODULUS(GPA) }\end{array}$ & $\begin{array}{c}\text { POISSON'S } \\
\text { RATIO }\end{array}$ \\
\hline STEEL & 7850 & $200 \mathrm{GPA}$ & 0.0 .3 \\
\hline
\end{tabular}

\section{FINITE ELEMENT MODELLING}

3D modeling of scissor lifting Table

The Scissor lifting table modelling done in Solid works Software with the part modeling for model the individual components by extrude boss, revolve options and all individual components are assembled.

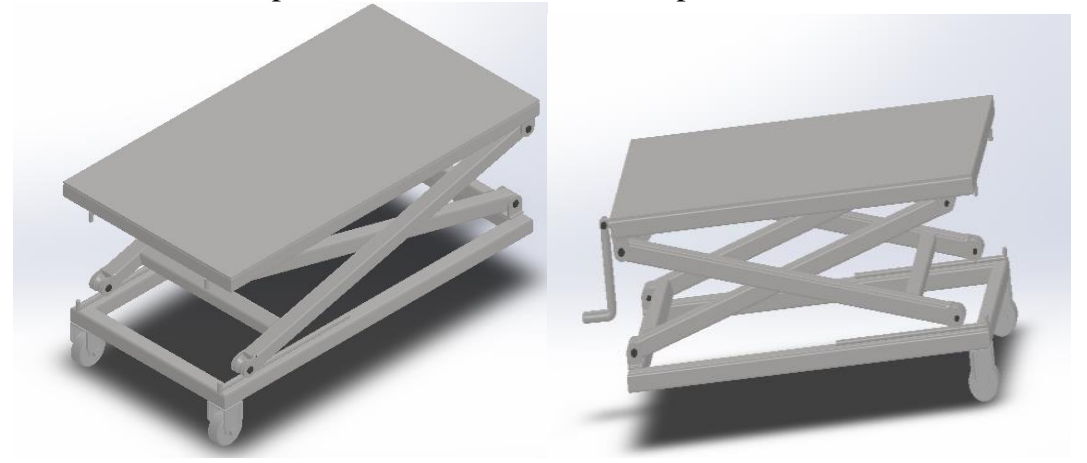

Fig 1. 3D Model of Scissor lifting Table 


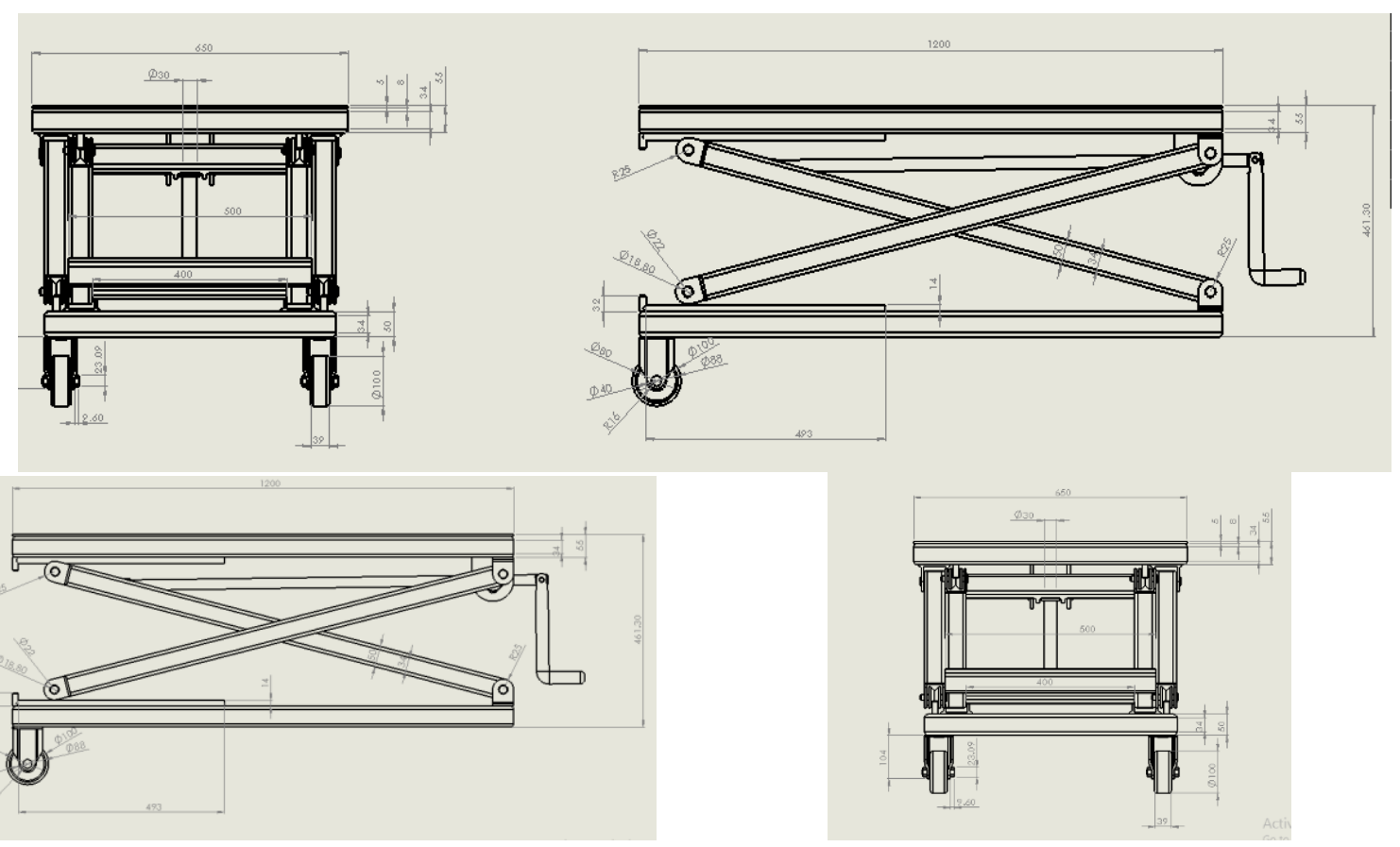

Mesh and Boundary conditions

Fig 2. Drafting model of the scissor lifting table

During the Finite element analysis grid independence check is done for better results with the nodes of 338754 and tetrahedral elements of 191641.The boundary conditions of this scissor lifting table analysis is various weight of $50 \mathrm{KG}, 75 \mathrm{KG}, 100 \mathrm{KG}$ and $125 \mathrm{KG}$ was given for this analysis.



Fig1.Boundary condition for scissor lifting table

RESULT AND DISCUSSIONS

TOTAL DEFORMATION RESULTS
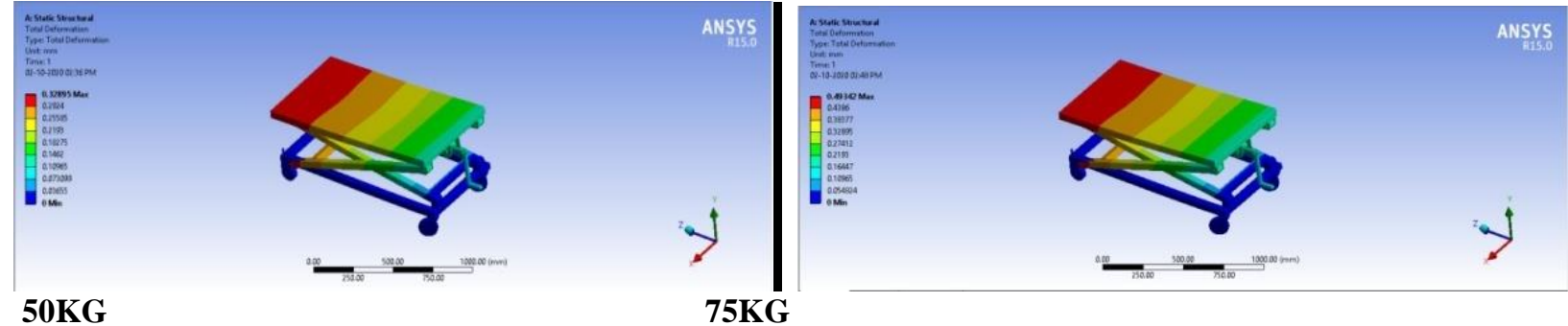

50KG 75KG 


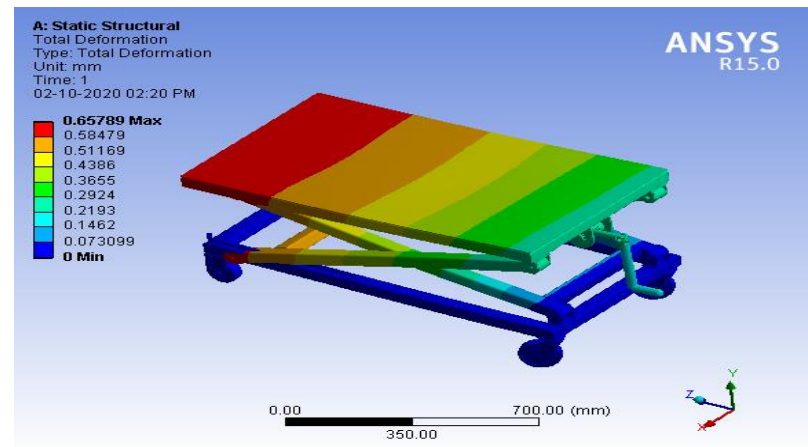

100KG

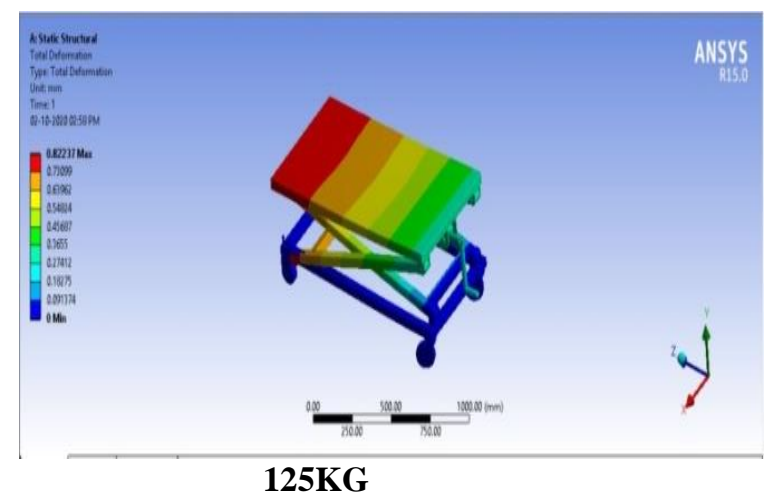

125KG

Fig2.total deformation results of scissor lifting table



Graph 1.total deformation results

MAX PRINCIPLE STRESS RESULTS

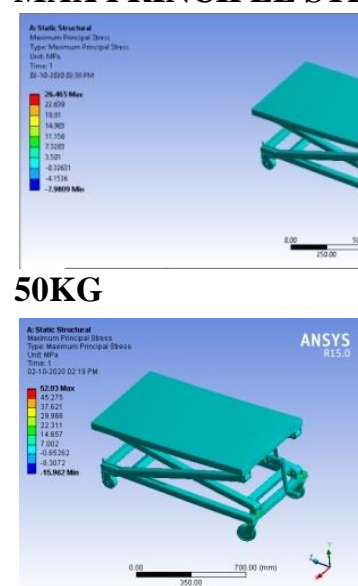

100KG
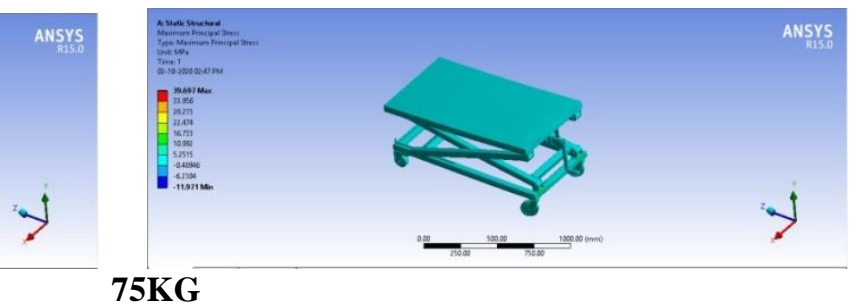

$75 \mathrm{KG}$

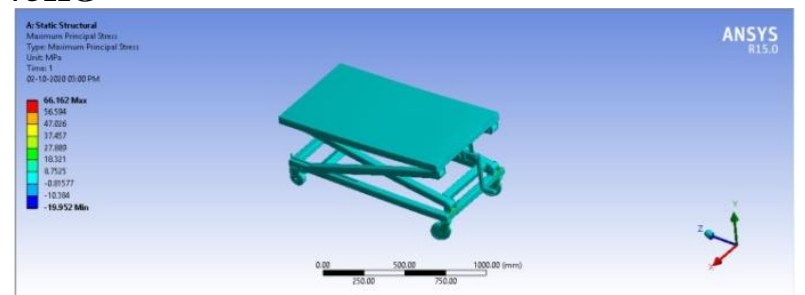

125KG

Fig3.maximum stress results of scissor lifting table

Table3.maximum principle stress results 
FEA Analysis For Scissor Lifting Table

\begin{tabular}{|l|l|l|l|l|}
\hline $\begin{array}{l}\text { MAX } \\
\text { PRINCIPLE } \\
\text { STRESS }\end{array}$ & 50KG & 75KG & 100KG & 125KG \\
\hline STEEL & 26.465 & 36.692 & 52.93 & 66.162 \\
\hline
\end{tabular}

\section{MAX PRINCIPLE STRESS(MPa)}



\section{SHEAR STRESS RESULTS}
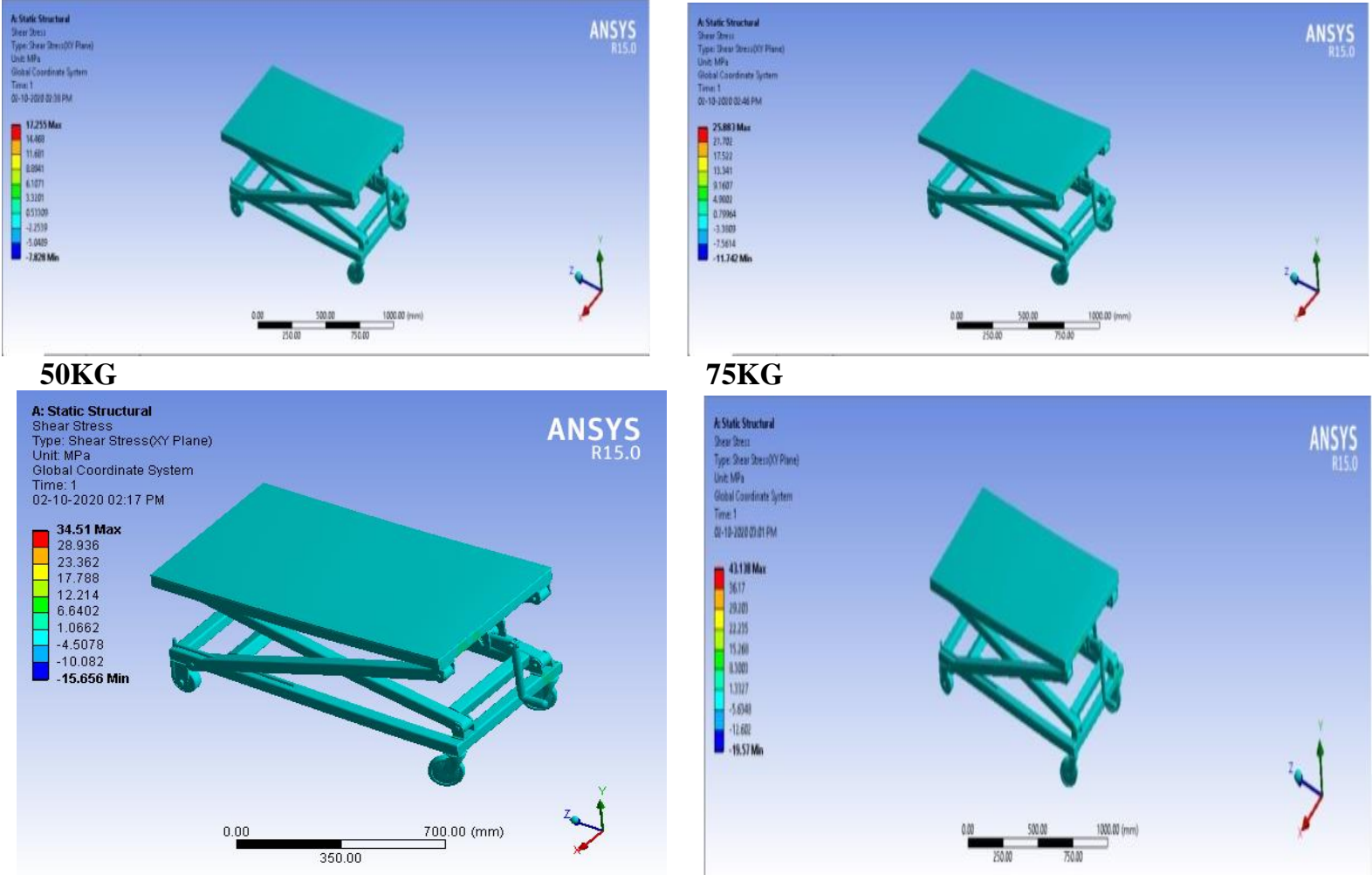

$100 \mathrm{KG}$

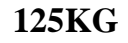

Fig4.shear stress results of scissor lifting table

Table4.shear stress results 


\begin{tabular}{|c|c|c|c|c|}
\hline $\begin{array}{c}\text { SHEAR } \\
\text { STRESS }\end{array}$ & 50KG & 75KG & 100KG & 125KG \\
\hline STEEL & 17.255 & 25.883 & 34.51 & 43.138 \\
\hline
\end{tabular}

\section{SHEAR STRESS(MPa)}

50

40

30

20

10

0
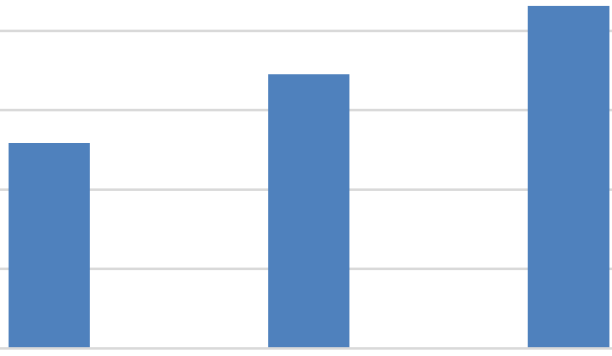

50KG

75KG

$100 K G$

125KG

Graph3.shear stress results

\section{STRAIN RESULTS}
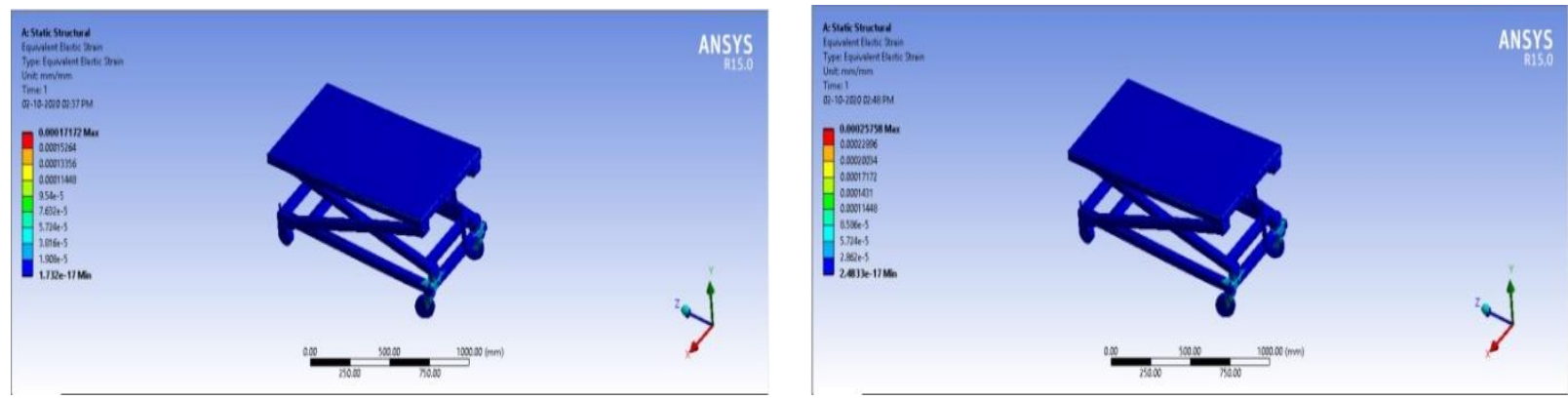

$50 \mathrm{KG}$

75KG
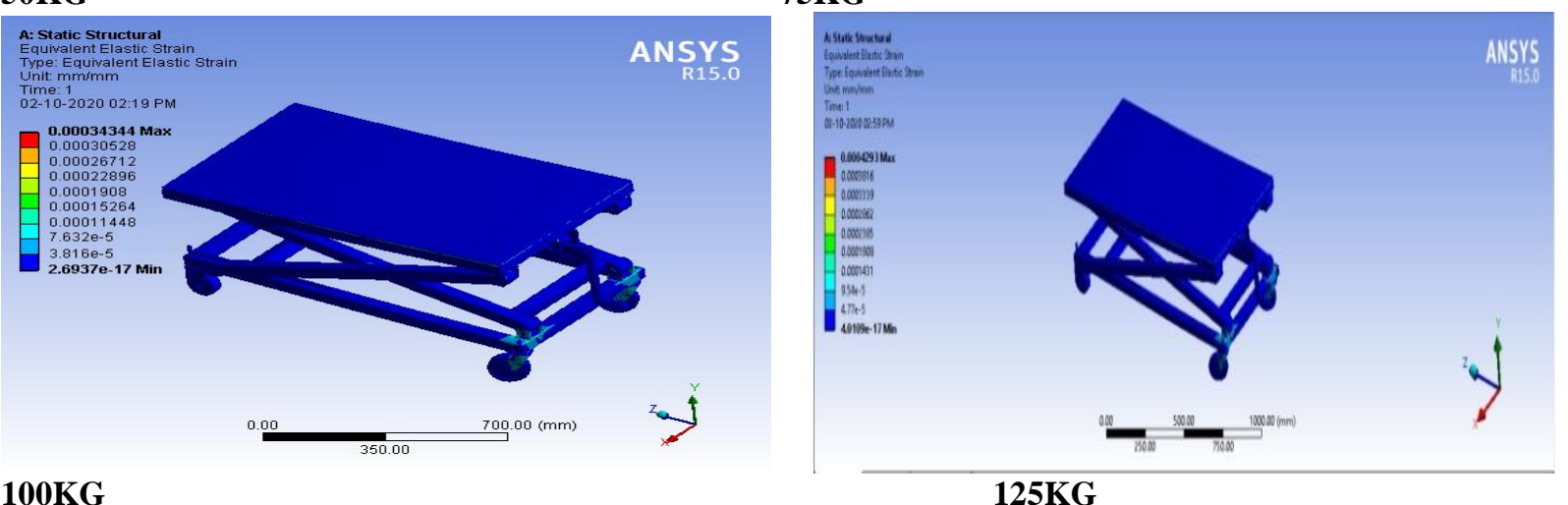

100KG

125KG

Fig5.strain results of scissor lifting table

Table5.strain results

\begin{tabular}{|c|c|c|c|c|}
\hline STRAIN & 50KG & 75KG & 100KG & 125KG \\
\hline STEEL & 0.000172 & 0.000258 & 0.000343 & 0.000429 \\
\hline
\end{tabular}


FEA Analysis For Scissor Lifting Table



Graph4.strain results

\section{STRESS INTENSITY RESULTS}

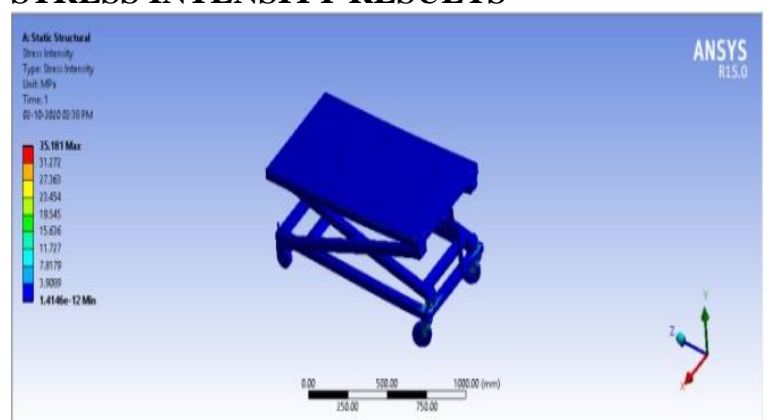

50KG

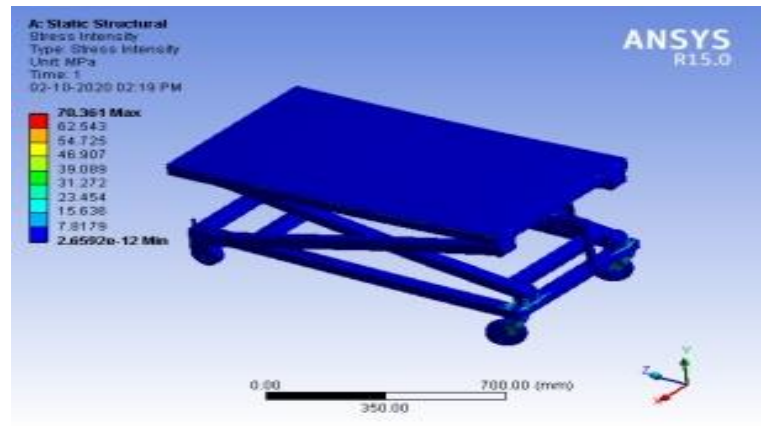

100KG

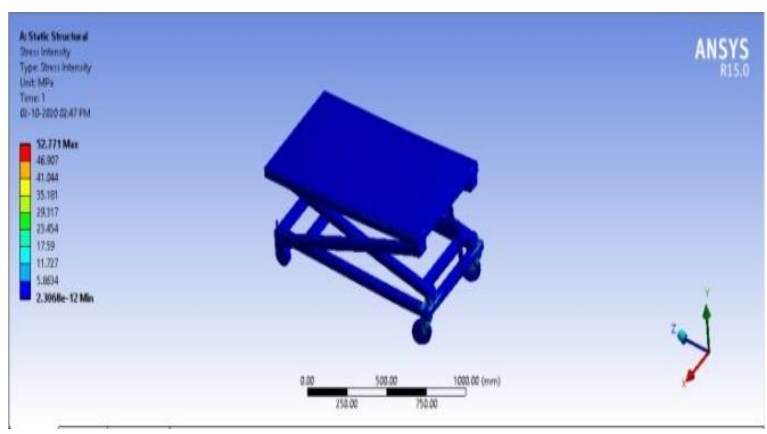

75KG

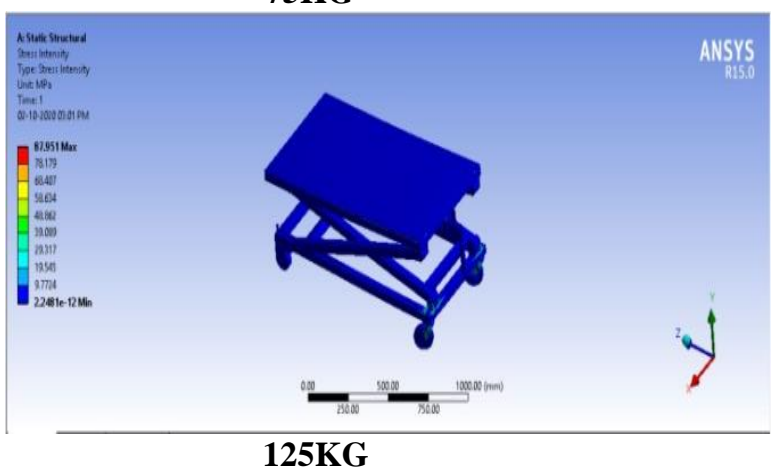

Fig6.stress intensity results of scissor lifting table Table6.stress intensity results

\begin{tabular}{|c|c|c|c|c|}
\hline $\begin{array}{c}\text { STRESS } \\
\text { INTENSITY }\end{array}$ & $\mathbf{5 0 K G}$ & $\mathbf{7 5 K G}$ & $\mathbf{1 0 0 K G}$ & $\mathbf{1 2 5 K G}$ \\
\hline STEEL & 35.181 & 52.771 & 70.361 & 87.951 \\
\hline
\end{tabular}




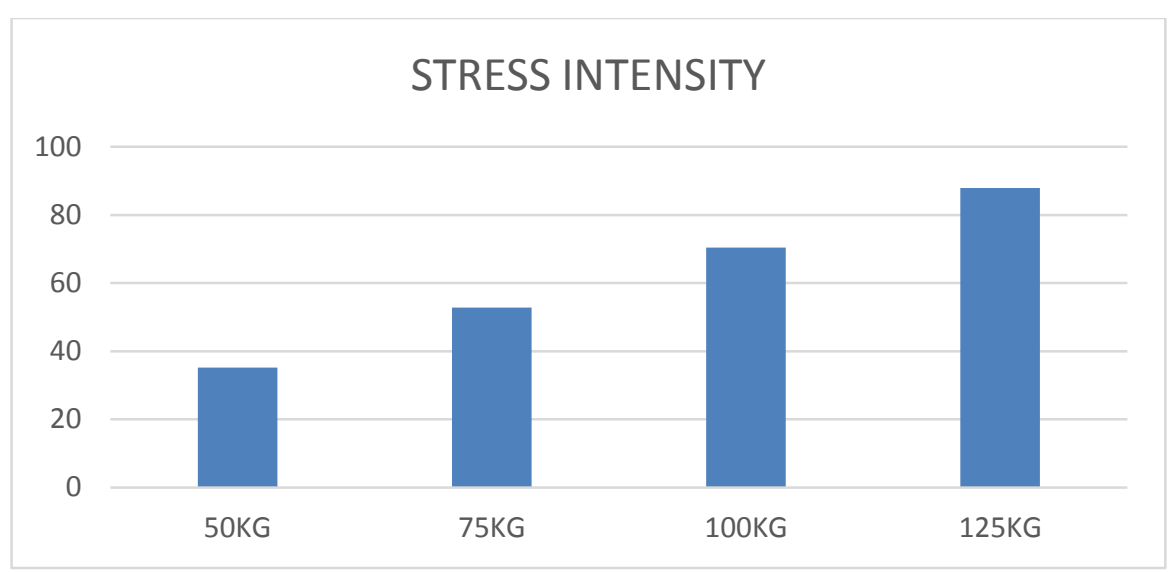

\section{STRESS RESULTS}



100KG

Graph5.stress intensity results

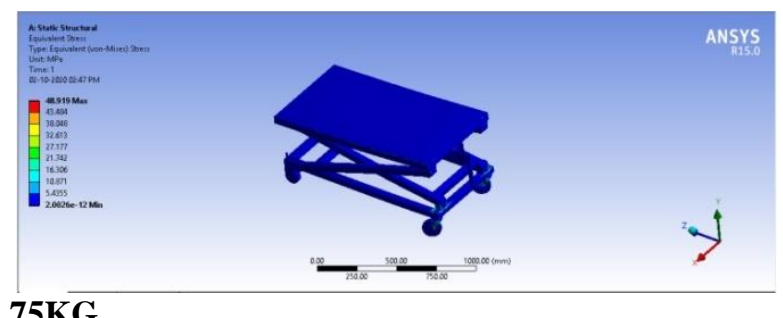

75KG

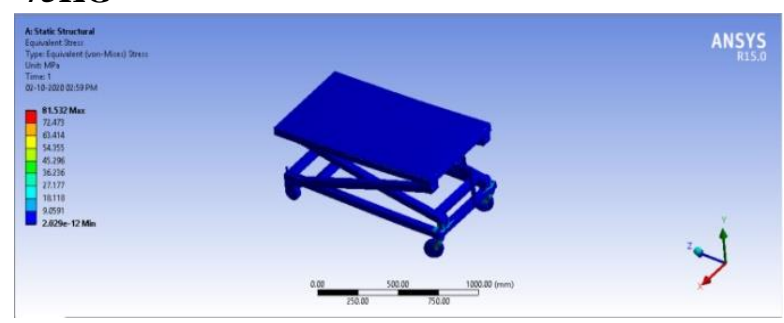

125KG

Fig7.stress results of scissor lifting table

Table7.stress results

\begin{tabular}{|c|c|c|c|c|}
\hline STRESS & 50KG & 75KG & 100KG & 125KG \\
\hline STEEL & 32.613 & 48.919 & 65.226 & 81.532 \\
\hline
\end{tabular}

STRESS (MPa)

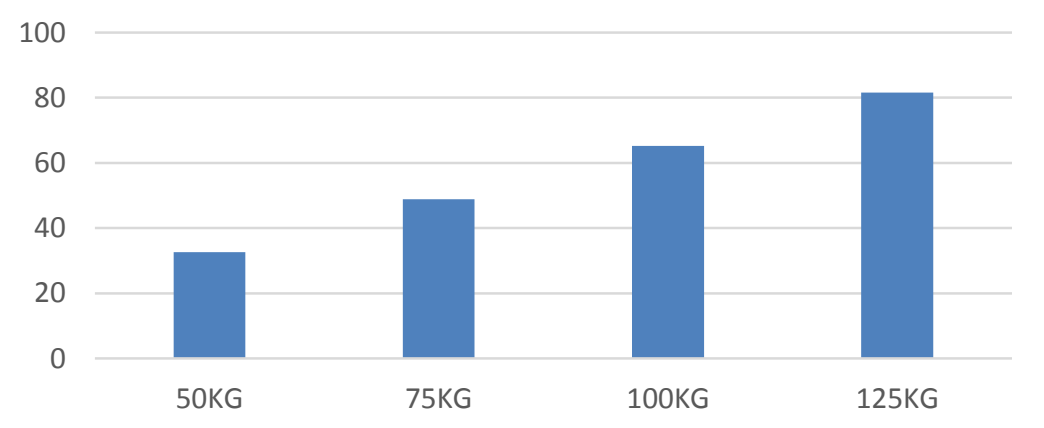

Graph6.stress results 


\section{CONCLUSION:}

The Scissor lifting table linear static analysis was done in ANSYS software with the various human weights of $50 \mathrm{~kg}, 75 \mathrm{~kg}, 100 \mathrm{~kg}$ and $150 \mathrm{~kg}$. Modeling of Scissor lifting table done in Solid works software the structural analysis results of total deformation, stress, principal stress, shear stress and strain results are taken for various weights if the human weight increase the result values will be increase linearly.

\section{REFERENCE:}

1. Christopher S. Pan, A.H., Michael McCann, Mei-Li Lin, Kevin Fearn, Paul Keane, Aerial lift fall injuries: A surveillance and evaluation approach for targeting prevention activities. Journal of Safety Research, 2007

2. McCann, M., Deaths in construction related to personnel lifts, 1992-1999. Journal of Safety Research, 34, 507-514.

3. Riley, W.F., Sturges, L.D. and Morris, D.H., Mechanics of Materials, 5th Edition, 1999, John Wiley \& Sons, Inc., United States of America.

4. Material Handling Industry of America (MHIA), Safety Requirements for Industrial Scissors Lifts. 1994, Charlotte: ANSI.

5. S. Mingzhou, G. Qiang, G. Bing, Finite element analysis of steel members under cyclic loading, Finite Elements in Analysis and Design. 39 (1) (2002), pp. 43-54 